\title{
Identification of Metallurgical Reactions and Their Effect on the Mechanical Properties of 17-7 PH Stainless Steel
}

\author{
H. C. Burnett, R. H. Duff, and H. C. Vacher
}

(January 17, 1962)

\begin{abstract}
In order to study the relationship between the metallurgical reactions that occur during aging treatments of $17-7 \mathrm{PH}$ and the accompanying changes in mechanical properties, samples of $0.0025 \mathrm{in}$. thick foil, annealed at $1950^{\circ} \mathrm{F}$ for $1 / 2$ hour and then conditioned at, $1400{ }^{\circ} \mathrm{F}$ for $1 \frac{1}{2}$ hours, were given aging treatments at 850 to $1150{ }^{\circ} \mathrm{F}$. Bulge test specimens, punched from the aged samples, were tested and used for metallographic, X-ray diffraction and electron diffraction examinations. Electron diffraction patterns obtained from selected areas in carbon extraction replicas showed the presence of ordered ferrite $\left(\mathrm{B}_{2} \mathrm{CsCl}\right.$ type $\mathrm{BCC}$ structure) in specimens aged 68 hours at $1050^{\circ} \mathrm{F}$. The aging treatments, bulge test data, and austenite contents obtained at $1050{ }^{\circ} \mathrm{F}$ indicated that the abrupt increase in strength and loss in ductility were caused by immediate formation of the ordered ferrite constituent, but the subsequent rapid recovery of ductility and slower loss in strength were caused by a reversion of random ferrite to austenite. At temperatures of $970{ }^{\circ} \mathrm{F}$ and below, there was no reversion and after the abrupt increase in strength and loss in ductility there was no further change in properties.
\end{abstract}

\section{Introduction}

Recent developments in the metallurgy of precipitation hardening stainless steels have been reviewed by Lena [1] ${ }^{1}$ and by Ludwigson and Hall [2]. These alloys were developed and are being used to meet the material demands associated with the design and construction of missiles and aircraft for high speed flight. Their important metallurgical characteristics are their good formability in the annealed condition and their ability to be hardened by subsequent heat treatments. Of these steels the 17-7 PH stainless steel has been considered to be truly a precipitation hardenable alloy yet until recently very little was known about the hardening mechanism.

It is well established that the soft condition of 17-7 PH consists mainly of austenite. During the $1400{ }^{\circ} \mathrm{F}$ conditioning treatment, carbides of the $\mathrm{M}_{23} \mathrm{C}_{6}$ type are precipitated at the grain boundaries thereby depleting the austenite grains of carbon and chromium. The $\mathrm{M}_{\mathrm{s}}$ point is no longer supressed and the austenite transforms to martensite on cooling and higher strength properties are obtained. Additional heat treatment (aging) at a still lower temperature results in hardening beyond that resulting from the austenite-martensite transformation. This increase in mechanical properties has been postulated to be the result of a fine precipitate within the martensite grains during the heat treatment. It is these metallurgical reactions and their relationship to changes in the mechanical properties that have been the subject of this investigation in working out a hardening mechanism for the 17-7 PH alloy.

Recently (1960) Underwood and associates [3] in working with specially prepared single crystals having the composition $\mathrm{Fe}, 17 \mathrm{Cr}, 7 \mathrm{Ni}, 2 \mathrm{Al}^{2}$ identified

\footnotetext{
${ }^{1}$ Figures in brackets indicate the literature references at the end of this paper.
}

2 The number preceding a symbol of an element is the weight percent. a microconstituent that had the structure of ordered ferrite, that is, the $\mathrm{B}_{2} \mathrm{CsCl}$ type cubic structure. They concluded from their work that ordered ferrite was the hardening agent in the 17-7 PH steel but did not show its relationship to strength and ductility. The ordered ferrite type structure was found by Bradley $[4,5,6,7]$ as early as 1938 to coexist with the ferrite type structure (martensite, delta-ferrite) and to have a large range of stability in the $\mathrm{Al}-\mathrm{Fe}-\mathrm{Ni}$ system. Bradley [4] has shown that X-ray diffraction results indicate than an alloy containing $5.4 \mathrm{Ni}, 2.5 \mathrm{Al}, 92 \mathrm{Fe}$ was constituted of both ferrite and ordered ferrite structure type phases. The ordered ferrite phase could not be observed in the microstructure by conventional metallography because the ordered ferrite particles were less than $100 \mathrm{~A}$ in diameter. Later, however, Bradley $[6,7]$ showed that in an alloy containing 11 $\mathrm{Ni}, 5 \mathrm{Al}, 84 \mathrm{Fe}$, the ferrite phase broke down into a mixture of ferrite and ordered ferrite, and after heating at $750{ }^{\circ} \mathrm{C}\left(1382{ }^{\circ} \mathrm{F}\right)$ for nine weeks the two phases could be clearly resolved in the microstructure. The microstructures that developed in the $\mathrm{Fe}-\mathrm{Ni}-\mathrm{Al}$ alloys at different temperatures were similar to those that have been postulated for the $17-7 \mathrm{PH}$ alloy.

Krauss and Averbach [8] showed that some of the ferrite phase reverted back to the austenite phase during the precipitation hardening treatments, also that hardness values and retained austenite contents appear to be unrelated. Carwile and Rosenberg [9] also showed that some of the ferrite phase had reverted back to the austenite phase. They, however, postulated that the increase in austenite was not an increase in the random A1 type structure but possibly an indication of the formation of ordered austenite, a phase having the $\mathrm{L}_{2} \mathrm{Cu}_{3} \mathrm{Au}$ type structure. The ordered austenite type structure has been identified as the hardening agent in nickel base heat-resisting alloys [10]. 
The foregoing investigations have left several questions unanswered or unconfirmed by experiment which it is the purpose of this investigation to attempt to answer. For convenience the phases austenite, ferrite, and ordered ferrite have been designated as $\gamma \mathrm{Fe}, \alpha \mathrm{Fe}$, and $\alpha^{\prime}$, respectively.

\section{Materials and Procedure}

When it is desired to explore the effect of heat treatment on mechanical properties, hardness tests are often used as an index. The information obtained is not always adequate because mechanical properties, such as yield stress, tensile strength, and ductility, are affected differently by different factors. To overcome this difficulty and to have the advantage of many small uniform specimens, a bulge tester [11] was built to test $3 / 4 \mathrm{in}$. diameter disks of $0.0025 \mathrm{in}$. thick foil. Figure 1 shows a typical fractured specimen of 17-7 PH alloy after aging. This test will give values for a nominal yield stress and ductility. In this case, yield criterion was chosen as the pressure in pounds per square inch required to produce a small predetermined permanent bulge height [11]. Uniformity in thickness was important in obtaining good precision, and was assured by selecting a set of 5 punched disks for testing whose weight agreed to $1 \mathrm{mg}$, equivalent to 1 percent of the thickness. The bulge height at failure was taken as a relative measure of ductility.

In addition to a nominal yield pressure and a measure of ductility, the bulge test gives a value for the biaxial tensile strength. The uncertainties involved in computing this value tend to make it unreliable, but it can be useful for comparative purposes. Table 1 lists the tensile strength for 17-7 PH foil in two conditions, calculated using the simple formulas for a thin-shelled sphere. The table also lists typical uniaxial tensile strength values for the two conditions, and it can be seen that they are not far different from the biaxial values obtained by the assumption of a spherical bulge.

The 17-7 PH foil was obtained through the courtesy of the Armco Steel Co. Initially it was in the annealed condition, $1950{ }^{\circ} \mathrm{F}$ for $1 / 2 \mathrm{hr}$, air cooled, and had the following composition: $0.10 \mathrm{C}, 17.6 \mathrm{Cr}$, $7.3 \mathrm{Ni},<0.2 \mathrm{Mo}, 1.0 \mathrm{Al}, 0.030 \mathrm{~N}$.

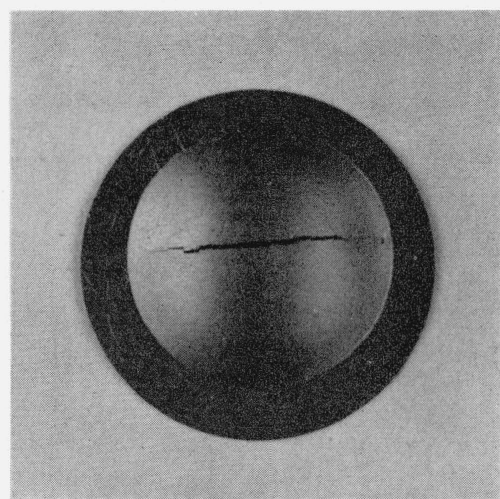

Figure 1. Typical bulge test fracture in $17-7$ PH alloy after the TH 1050 aging treatment.
Samples of foil, 1 in. by 4 in. by 0.0025 in. were heat treated in a vertical inconel tube furnace evacuated to $25 \times 10^{-3} \mathrm{~mm} \mathrm{Hg}$. In order to reduce surface reactions to the minimum, samples were enclosed in tight-fitting envelopes made from stainless steel foil. Little or no coloration was observed after the heat treatments. Four envelopes could be suspended in the hot zone of the furnace from the end of a $1 / 4$ in. diameter vertical stainless steel tube in which there was a chromel-alumel thermocouple, the junction of which was adjusted so as to be near the envelopes. The envelopes were cooled rapidly by pulling the tube into the top section of the furnace tube that was cooled by a water jacket.

TABLE 1. Comparison of nominal tensile strength values obtained by bulge and tensile load testers

\begin{tabular}{|c|c|c|c|}
\hline \multicolumn{2}{|l|}{ Bulge tests } & \multicolumn{2}{|l|}{ Tensile load tests ${ }^{2}$} \\
\hline Condition & $\begin{array}{l}\text { Tensile } \\
\text { strength } 1\end{array}$ & Condition & $\begin{array}{l}\text { Tensile } \\
\text { strength }\end{array}$ \\
\hline $\begin{array}{l}\text { Annealed } \\
\text { TH } 1050^{\circ} \mathrm{F}-1 \frac{1}{2} \mathrm{hr}\end{array}$ & $\begin{array}{l}l b / i n .^{2} \\
137,000 \\
182,000\end{array}$ & $\begin{array}{l}\text { Annealed } \\
\text { TH } 1050^{\circ} \mathrm{F}-1 \frac{1}{2} \mathrm{hr}\end{array}$ & $\begin{array}{l}l b / \text { in. }^{2} \\
130,000 \\
200,000\end{array}$ \\
\hline
\end{tabular}

\footnotetext{
Computed from the following relationships
(a) Assuming that the bulge is spherical $R=\frac{4 d^{2}+D^{2}}{8 d}$

(b) The stress in a pressurized, thin-shelled sphere. $S=\frac{P R}{2 t}$.

2 Taken from reference 2 .
}

All of the samples were given the recommended commercial conditioning heat treatment, that is, heating at $1400{ }^{\circ} \mathrm{F}$ for $1 \frac{1}{2} \mathrm{hr}$, followed by rapid cooling to room temperature. After this treatment the unopened envelopes were given one of the aging treatments as listed in tables 2,3 , and 4 .

Four $3 / 4$ in. diam disks were punched from each 1 in. by $4 \mathrm{in}$. heat-treated sample and used in the bulge tests and for metallographic and X-ray diffraction examinations.

The metallographic examinations were made by the extraction replica technique [12] with an electron microscope. A short steel wire (0.039 in. diam) was spot-welded to the edge of each disk for convenience in handling. It was cleaned and dried in three operations:

(1) Electropolished at $32 \mathrm{v}$ and $1.2 \mathrm{amp}$ until red flakes fell off, usually 1 to $3 \mathrm{~min}$, in an electrolyte consisting of:

7 parts glacial acetic acid

2 parts acetic anhydride

1 part perchloric acid.

(2) It was then cleaned further with an ultrasonic cleaner in a detergent solution until any adhering film was removed;

(3) Then washed with alcohol and dried.

The clean disk then was placed in a vacuum evaporator [13] and a moderately thick film of carbon was deposited at normal incidence on it. The carbon 
TABLE 2. Percent $\gamma F e,{ }^{a}$ yield pressure, ${ }^{b}$ and ductility ${ }^{c}$ of the $1 \gamma-\gamma P H$ alloy after aging treatments

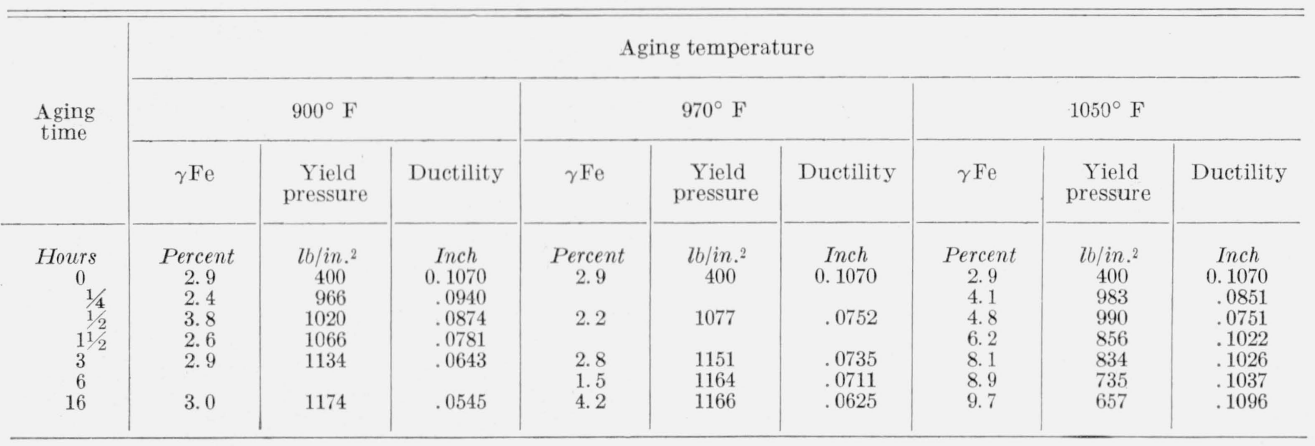

a Percent $\gamma \mathrm{Fe}$ of the $\alpha \mathrm{Fe}+\gamma \mathrm{Fe}$ content.

a Oil pressure required to produce a permanent bulge height of 0.0119 inch.
cBulge height at fracture.

film was stripped off by electropolishing at $32 \mathrm{v}$ and $1.2 \mathrm{amp}$ in an electrolyte consisting of:

1 part perchloric acid

20 parts glacial acetic acid

A fresh stripping solution was used for each specimen. The stripped carbon films were washed, placed on grids, and examined with the electron microscope. Typical electron micrographs of the extraction replicas are shown in figure 2 and will be discussed in a later section.

TABLE 3. Percent $\gamma \mathrm{Fe}$, yield pressure, and ductility of the $17-7$ PH alloy after $1 \frac{1}{2}$ hours aging at different temperatures

\begin{tabular}{c|c|c|c}
\hline \hline $\begin{array}{c}\text { Aging } \\
\text { temperature }\end{array}$ & $\gamma \mathrm{Fe}$ & $\begin{array}{c}\text { Yield } \\
\text { pressure }\end{array}$ & Ductility \\
\cline { 2 - 3 } & & lb/in.2 & Inch \\
${ }^{\circ} \mathrm{F}$ & 2.14 & 1000 & 0.0952 \\
850 & 2.62 & 1066 & .0781 \\
900 & 2.79 & 1155 & .0689 \\
950 & 3.58 & 1066 & .0796 \\
1000 & 6.20 & 856 & .1022 \\
1050 & 15.48 & 510 & .1124 \\
1150 & & &
\end{tabular}

TABLE 4. Percent $\gamma \mathrm{Fe}$ in the $1 \gamma-\gamma$ PH alloy at stages in a schedule of aging treatments at high and low temperatures

\begin{tabular}{c|l|c}
\hline \hline \multirow{2}{*}{ Stage } & Immediate prior treatment & $\gamma \mathrm{Fe}$ \\
\cline { 3 - 3 } & & \\
\cline { 3 - 3 } $\mathrm{A}$ & Initial, as received & Percent \\
$\mathrm{B}$ & $1400^{\circ} \mathrm{F}$ for 16 hours, then & 2.3 \\
$\mathrm{C}$ & $-320^{\circ} \mathrm{F}$ for 8 hours, then & 1.2 \\
$\mathrm{D}$ & $1065^{\circ} \mathrm{F}$ for 16 hours, then & 15.9 \\
$\mathrm{E}$ & $-320^{\circ} \mathrm{F}$ for 24 hours. & 10.1 \\
\hline
\end{tabular}

The presence of preferred orientation in the foil after the conditioning and aging treatments precluded an accurate determination of the austenite content by X-ray diffraction; however, the change in austenite content resulting from a heat treatment could be followed with a fair degree of precision. This was done by determining the relative integrated intensity of the 200 line of austenite as compared to that of the 200 line of martensite. The values were computed from data obtained from diffractometer charts. Values for the $R^{3}$ factor [8] were taken as 15.0 and 8.85 for the $\gamma \mathrm{Fe}$ and $\alpha \mathrm{Fe}$ phases respectively. The handling and placing of the disk specimens in the diffractometer were facilitated

'The $R$ factor is the product of factors affecting the intensity of different lines by mounting each specimen on a $1 \frac{1 / 4}{4}$ in. diameter by $1 / 4$ in. thick disk of Lucite with double-coated pressure-sensitive tape.

X-ray diffraction patterns were obtained with a $57 \mathrm{~mm}$ diameter powder camera from residues that remained after dissolving several cleaned disks in aqua regia. The residue was washed with water several times by decantation, using a centrifuge to facilitate settling.

\section{Results and Discussion}

By using the previously described carbon extraction replica technique it was possible to show the ordered ferrite constituent in the microstructure, figure 2d, after long aging treatments. Electron diffraction patterns obtained from these areas gave lines that corresponded to the $\mathrm{B}_{2} \mathrm{CsCl}$ type structure, table 5 and figure 3 . The patterns included the three superlattice lines, 100,111 , and 210 . The lines in the X-ray diffraction patterns obtained from the residues could be indexed on the basis that they were mixtures of the $\mathrm{M}_{23} \mathrm{C}_{6}$ carbide [14] and $\alpha^{\prime}$ [4]. The structural data are given in tables 5 and 6. The lattice constants of martensite and ordered ferrite were $2.8714 \mathrm{~A} \pm 0.00005$ and 2.909 $\mathrm{A} \pm 0.006$, respectively, after $68 \mathrm{hr}$ aging treatments

TABLE 5. Electron and X-ray diffraction patterns obtained for $\alpha^{\prime}$

\begin{tabular}{|c|c|c|c|c|c|c|c|c|}
\hline \multirow{2}{*}{$h k l$} & \multicolumn{2}{|c|}{$\alpha^{1}$} & \multicolumn{3}{|c|}{$\begin{array}{l}\text { Electron diffraction } \\
\text { pattern }\end{array}$} & \multicolumn{3}{|c|}{$\begin{array}{l}\text { X-ray diffraction } \\
\text { pattern }\end{array}$} \\
\hline & $d$ & $I$ & $d$ & $I$ & $a$ & $d$ & $I$ & $a$ \\
\hline $\begin{array}{l}100^{2} \\
110^{2} \\
111^{2} \\
200^{2} \\
210^{2} \\
211^{2} \\
220 \\
310^{2}\end{array}$ & $\begin{array}{l}A \\
2.878 \\
2.035 \\
1.660 \\
1.439 \\
1.287 \\
1.175 \\
1.018 \\
0.910\end{array}$ & $\begin{array}{r}M S \\
V V S \\
M W \\
S \\
M W \\
S \\
M \\
M\end{array}$ & $\begin{array}{l}\text { A } \\
2.93 \\
2.07 \\
1.67 \\
1.46 \\
1.30 \\
1.19 \\
1.02 \\
0.918\end{array}$ & $\begin{array}{c}100 \\
60 \\
80 \\
\end{array}$ & $\begin{array}{l}2.93 \\
2.93 \\
2.90 \\
2.92 \\
2.91 \\
2.92 \\
2.90 \\
2.9\end{array}$ & $\begin{array}{c}A \\
2.903 \\
2.041 \\
1.684 \\
1.463 \\
1.293 \\
1.192\end{array}$ & $\begin{array}{r}10 \\
100 \\
10 \\
20 \\
70 \\
30\end{array}$ & $\begin{array}{l}2.903 \\
2.890 \\
2.920 \\
2.926 \\
2.893 \\
2.922\end{array}$ \\
\hline \multicolumn{3}{|c|}{ Average } & & & 2. 91 & & & $\begin{array}{r}2.909 \\
\pm 0.006\end{array}$ \\
\hline
\end{tabular}

1 Values of $d$ calculated on basis that $a=2.878 \mathrm{~A}$, the average value obtained

by Bradley and Taylor [4, p. 369]. This phase was designated by them as $\boldsymbol{B}_{2}$.
2 Superlatice line of the ordered B CsCl type, cubic structure. 

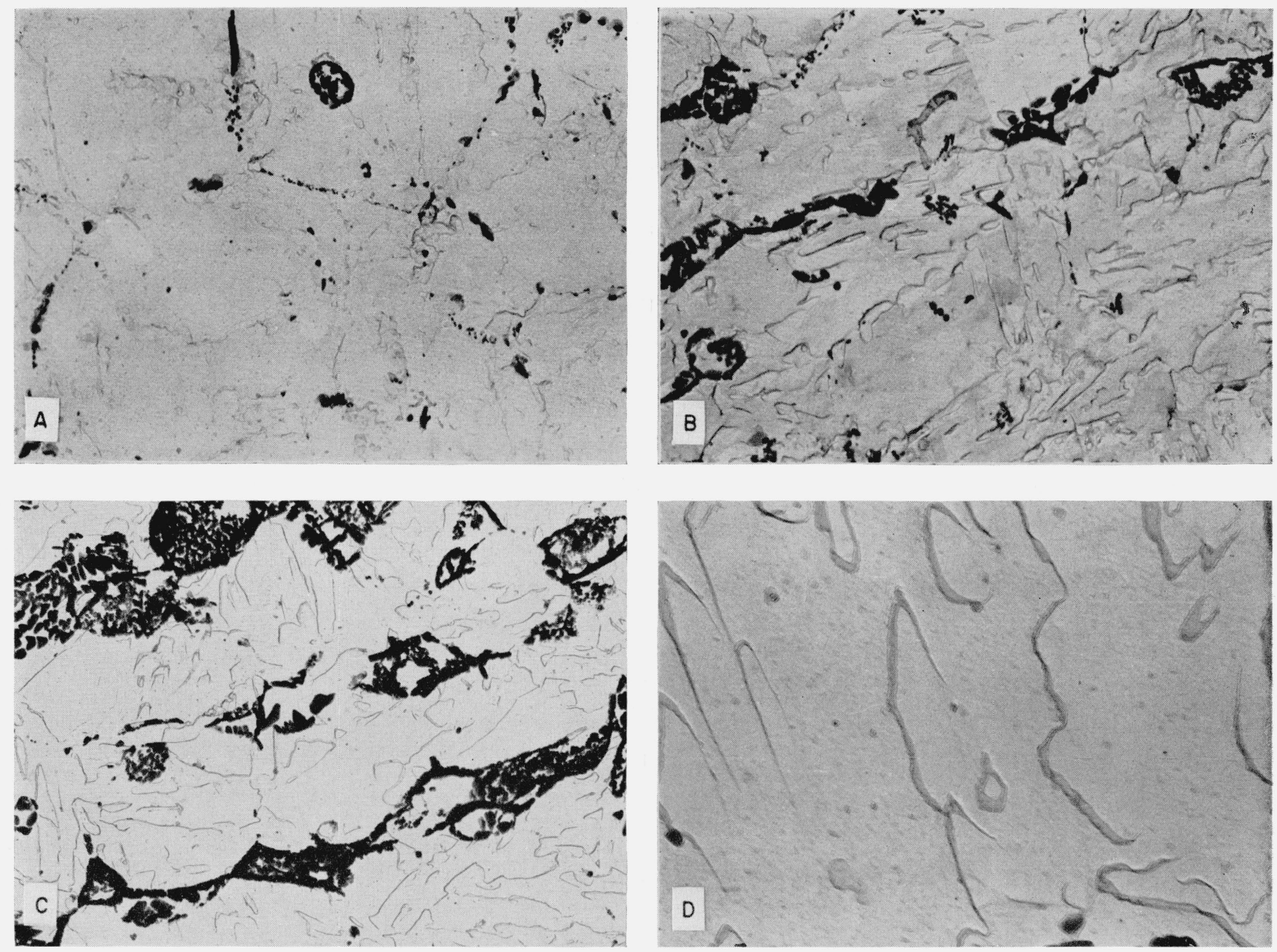

FiguRE 2. Electron micrographs of carbon extraction replicas of $1 \%-7$ PH alloy aged at $1050{ }^{\circ} \mathrm{F}$.

a after $1 / 4 \mathrm{hr} ; \mathrm{b}$, after $3 \mathrm{hr} ; \mathrm{c}$ and d, after $68 \mathrm{hr}$. Magnification: a,b,c, $\times 5000, \mathrm{~d}, \times 20,000$

The large black areas in $\mathrm{a}, \mathrm{b}$, and $\mathrm{c}$ and the small grey spots in d were identified by selected-area electron diffraction as being $\mathrm{M}_{23} \mathrm{C}_{6}$ carbide and $\alpha^{\prime}$ respectively. The elongated outlined areas are believed to be replicas of the reverted $\gamma \mathrm{Fe}$ constituent.

TABLE 6. Electron and X-ray diffraction patterns obtained from carbides precipitated in 17-7 PH stainless steel

\begin{tabular}{|c|c|c|c|c|c|c|}
\hline \multirow{2}{*}{$h k l$} & \multicolumn{2}{|c|}{$\mathrm{M}_{23} \mathrm{C}_{6} 1$} & \multicolumn{2}{|c|}{$\begin{array}{l}\text { Electron diffraction } \\
\text { pattern }\end{array}$} & \multicolumn{2}{|c|}{$\begin{array}{l}\mathrm{X} \text {-ray diffraction } \\
\text { pattern }\end{array}$} \\
\hline & $d$ & $I$ & $d$ & $I$ & $d$ & $I$ \\
\hline $\begin{array}{l}420 \\
422 \\
333 \\
440 \\
531\end{array}$ & $\begin{array}{l}2.375 \\
2.168 \\
2.044 \\
1.878 \\
1.796\end{array}$ & $\begin{array}{l}\mathrm{MS} \\
\mathrm{M} \\
\mathrm{S} \\
\mathrm{M} \\
\mathrm{M}\end{array}$ & $\begin{array}{l}2.40 \\
2.20 \\
2.03 \\
1.88 \\
1.79\end{array}$ & $\begin{array}{l}\mathrm{S} \\
\mathrm{M} \\
\mathrm{VS} \\
\mathrm{M}\end{array}$ & $\begin{array}{l}\text { 2. } 374 \\
2.166 \\
2.041 \\
1.888 \\
1.795\end{array}$ & $\begin{array}{r}80 \\
80 \\
100 \\
60 \\
50\end{array}$ \\
\hline $\begin{array}{l}620 \\
622 \\
644 \\
660 \\
555\end{array}$ & $\begin{array}{l}1.080 \\
1.602 \\
1.288 \\
1.252 \\
1.226\end{array}$ & $\begin{array}{l}\text { M } \\
\text { MW } \\
\text { M } \\
\text { MS } \\
\text { M }\end{array}$ & $\begin{array}{l}1.68 \\
1.60 \\
1.29 \\
1.24 \\
1.23\end{array}$ & $\mathrm{VS}$ & $\begin{array}{l}1.684 \\
1.605 \\
1.289 \\
1.252 \\
1.225\end{array}$ & $\begin{array}{l}10 \\
50 \\
20 \\
80 \\
70\end{array}$ \\
\hline $\begin{array}{l}753 \\
844 \\
933 \\
1040\end{array}$ & $\begin{array}{l}1.166 \\
1.084 \\
1.067 \\
0.968\end{array}$ & $\begin{array}{l}\mathrm{M} \\
\mathrm{S} \\
\mathrm{MW} \\
\mathrm{M}\end{array}$ & $\begin{array}{l}\text { 1. } 15 \\
1.10 \\
1.06 \\
1.983\end{array}$ & & $\begin{array}{l}1.167 \\
1.084 \\
1.068 \\
0.986\end{array}$ & $\begin{array}{r}30 \\
70 \\
5 \\
5\end{array}$ \\
\hline
\end{tabular}

1 Taken from reference [14].

Tests were conducted to demonstrate that the apparent increase in austenite found in the earlier work $[8,9]$ was unordered austenite. If the apparent increase were $\gamma \mathrm{Fe}$, then it would transform by a diffu-

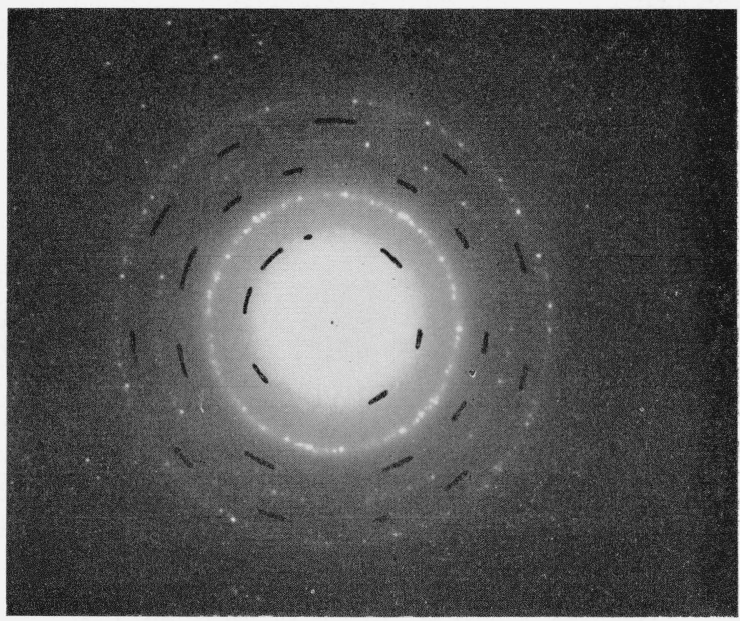

FIGURE 3. Electron diffraction pattern obtained from an area in a carbon extraction replica similar to that shown in figure $2 d$.

The superlattice lines listed in table 5 could be seen as spots in short ares on the photographic plate. To indicate the agreement of the locations of the short ares with the superlattice lines, dashed circles, whose diameters were computed from the average value of the lattice constant for $\alpha^{\prime}$ were drawn on the printed diffraction pattern. The spots in the short ares have nearly been obliterated
in reproduction. 
sionless reaction to $\alpha \mathrm{Fe}$ on cooling. Specimens were heat treated in a specific sequence, and individual samples at each stage of the sequence were tested to determine the apparent $\gamma \mathrm{Fe}$ content. The sequence of treatments and the results of the tests are given in table 4. The results show high retained-austenite content after cooling from 1950 to $1065^{\circ} \mathrm{F}$ but low retained-austenite content after cooling from 1400 ${ }^{\circ} \mathrm{F}$. This would be expected because the chemical compositions of the austenite present at 1950, 1400, and $1065^{\circ} \mathrm{F}$ would be different. This in turn would would cause the $M_{s}$ temperature to be different. A high $M_{s}$ temperature usually results in a low retained-austenite content. The chemical composition of the austenite can be estimated from phase diagrams [15, 16, and 17] and the $M_{s}$ temperature for each composition calculated [18], see table 7 . The values for the $M_{s}$ temperatures, although they can be considered only approximate, indicate that the retained austenite after aging at $1950{ }^{\circ} \mathrm{F}$ and $1065^{\circ} \mathrm{F}$ should be higher than that at $1400{ }^{\circ} \mathrm{F}$.

Further indication that the apparent increase in retained austenite after the $1065^{\circ} \mathrm{F}$ aging treatment was $\gamma \mathrm{Fe}$ was shown by the approximately 40 percent reduction in retained austenite, table 4, that resulted from the $-320^{\circ} \mathrm{F}$ cooling treatment even though the estimated $M_{s}$ temperature was quite low, $-123{ }^{\circ} \mathrm{F}$ (table 7 ). The foregoing considerations led to the conclusion that the apparent increase in retained austenite after the 1050 and $1065{ }^{\circ} \mathrm{F}$ treatments was the result of a reversion of martensite to austenite.

TABLE 7. The estimated chemical composition, $\mathrm{M}_{s}$, temperature and percentage of $\gamma \mathrm{Fe}$ in the $1 \gamma_{-\gamma} \mathrm{PH}$ alloy at different temperatures

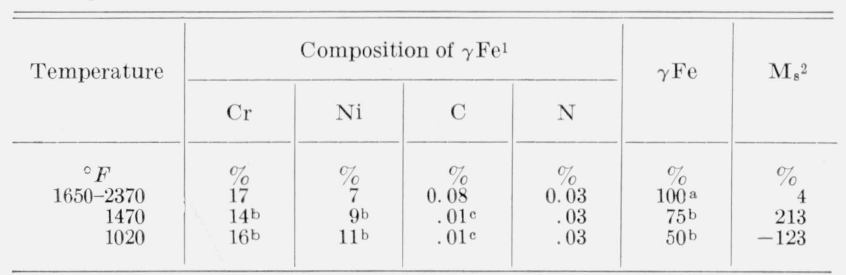

\footnotetext{
1 Balance iron plus residuals.

2 See reference [18].

a See reference $[15]$

See reference $[16]$

c See reference [17].
}

In figure 4 the values of yield pressure and ductility and percent $\gamma \mathrm{Fe}$ are plotted against time for aging at temperatures of 900,970 , and $1050{ }^{\circ} \mathrm{F}$. In these tests the initial condition was the 1400 treatment, that is, the alloy was heated at $1400{ }^{\circ} \mathrm{F}$ for $1 \frac{1}{2} \mathrm{hr}$. In this condition carbides were observed in the grain boundaries, the $\gamma \mathrm{Fe}$ content was 2.9 percent, and the yield pressure and bulge height were $400 \mathrm{lb} /$ in $^{2}$ and $1070 \times 10^{-4}$ in. It can be seen in the graphs that heating at $900{ }^{\circ} \mathrm{F}$ caused little or no change in the austenite content, at $970{ }^{\circ} \mathrm{F}$ there appeared to be a slight increase after $16 \mathrm{hr}$ and at $1050^{\circ} \mathrm{F}$ there was a definite increase reaching its maximum value in about $6 \mathrm{hr}$. The curves for yield pressure and ductility are similar at $900{ }^{\circ} \mathrm{F}$ and $970{ }^{\circ} \mathrm{F}$, the principal difference being that the maximum yield pressure and minimum ductility are approached in

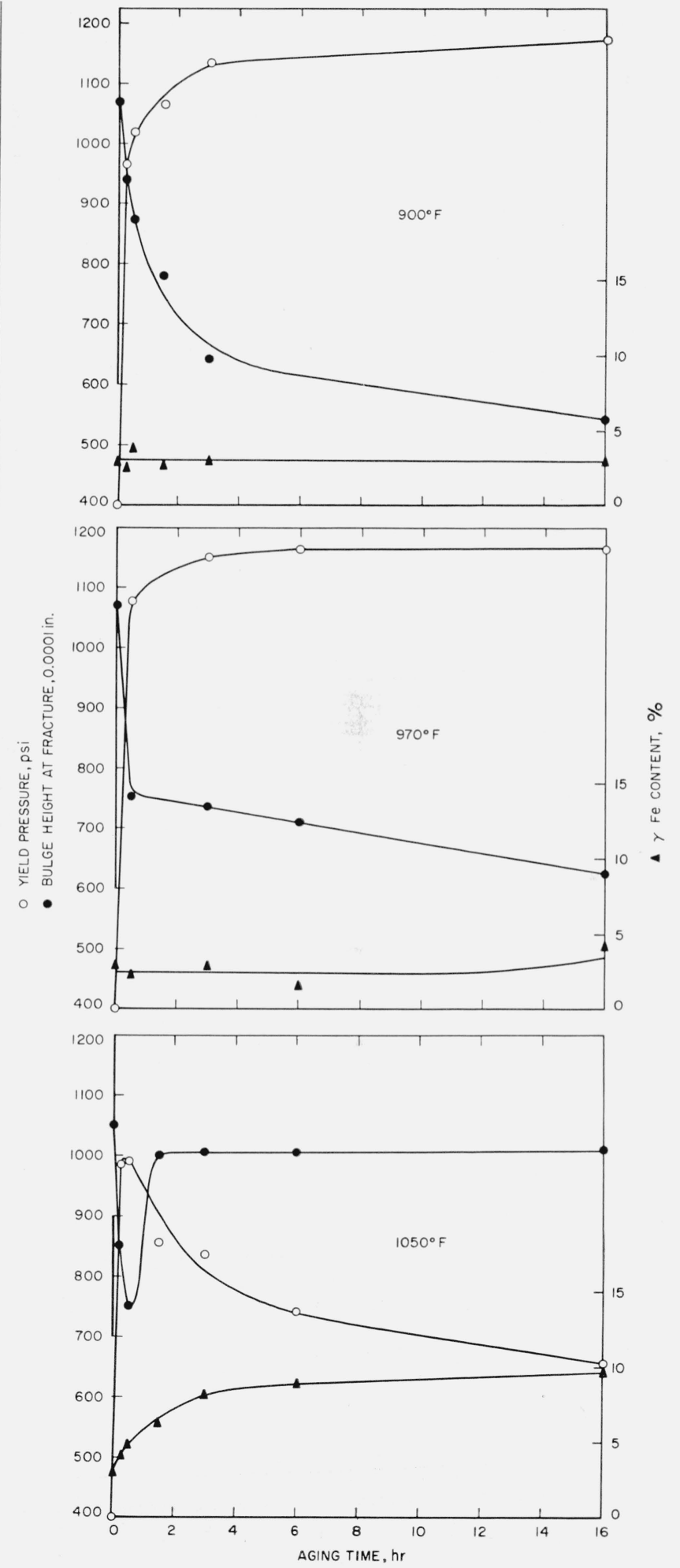

Figure 4. The effect of time at temperature on the strength, ductility, and $\gamma F$ e content of the $\gamma_{-\gamma} \gamma_{P H}$ alloy.

Prior treatment, $1 \frac{1 / 2}{\mathrm{hr}}$ at $1400^{\circ} \mathrm{F}$. 
a shorter time at $970^{\circ} \mathrm{F}$ than at $900^{\circ} \mathrm{F}$. There is a marked difference in the character of the yield pressure and ductility curves at $1050{ }^{\circ} \mathrm{F}$ as compared with those at $900{ }^{\circ} \mathrm{F}$ and $970{ }^{\circ} \mathrm{F}$. The yield pressure quickly $(1 / 2 \mathrm{hr})$ reaches the maximum, $1000 \mathrm{lb} / \mathrm{in}^{2}{ }^{2}$, and then slowly approaches the minimum of 660 $\mathrm{lb} / \mathrm{in}^{2}$, which is not so far from the initial value of $400 \mathrm{lb} /$ in. $^{2}$ The ductility quickly reaches the minimum, $750 \times 10^{-4}$ in., at $1 / 2 \mathrm{hr}$ but nearly recovers the initial value at $1 \frac{1}{2} \mathrm{hr}$. These curves have been interpreted as indicating that the effect of a precipitation of $\alpha^{\prime}$, as shown by the marked increase in strength and accompanying marked decrease in ductility, is immediate at temperatures in the range of 900 to $1050^{\circ} \mathrm{F}$ but that at $1050^{\circ} \mathrm{F}$ the reversion of $\alpha \mathrm{Fe}$ to $\gamma \mathrm{Fe}$ causes a rapid recovery of ductility and a much slower loss in strength. At lower temperatures, 970 and $900{ }^{\circ} \mathrm{F}$, there is little or no recovery in ductility or loss in strength because there is little or no change in the $\gamma \mathrm{Fe}$ content.

The pronounced immediate effect of the precipitation of $\alpha^{\prime}$ and the slower effect of the reversion of $\alpha \mathrm{Fe}$ to $\gamma \mathrm{Fe}$ on the strength and ductility are also indicated by the curves in figure 5 . In this case the specimens were aged for $1 \frac{1 / 2}{h r}$ at different temperatures. It can be seen that the reversals in the strength and ductility curves did not occur until after there was a slight increase in the $\gamma \mathrm{Fe}$ content, that is, near $950^{\circ} \mathrm{F}$.

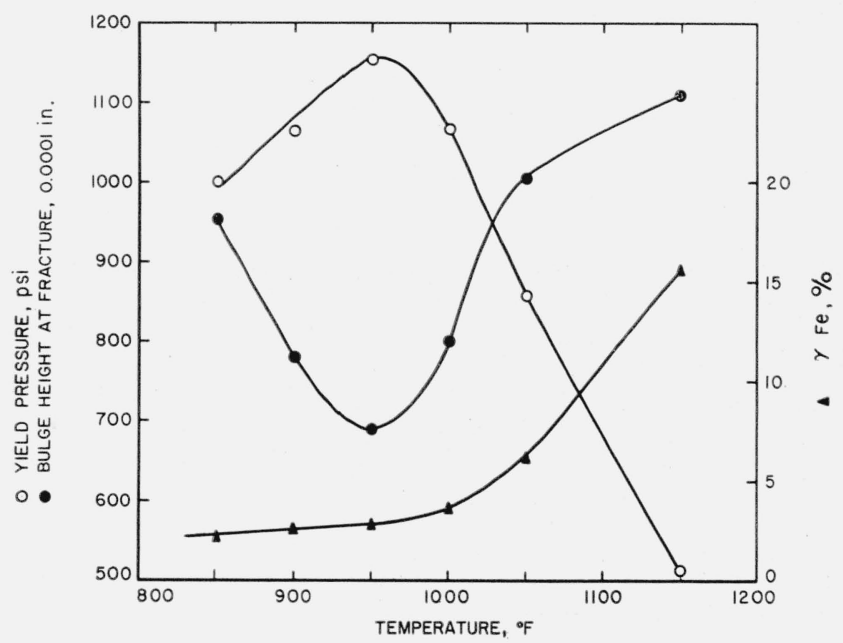

Figure 5. The effect of aging for $1 \frac{1}{2}$ hours at various temperatures on the strength, ductility, and $\gamma \mathrm{Fe}$ content of the $1 \gamma_{-\gamma}$ PH alloy.

Prior treatment. $1 \frac{1}{2} \mathrm{hr}$ at $1400{ }^{\circ} \mathrm{F}$,

\section{Summary and Conclusions}

Samples of 17-7 PH alloy foil, 0.0025 in. thick, after heating at $1400{ }^{\circ} \mathrm{F}$ for $1 \frac{1 / 2}{2} \mathrm{hr}$, were given heat treatments in which time at temperature and temperature were variables. Specimens in the form of $3 / 4$ in. diameter disks, were punched from the heattreated samples, tested and examined as follows:

(1) Strength and ductility were tested by a bulge tester.
(2) Selected areas of extraction replicas were examined by electron diffraction.

(3) The percentage of austenite in the austenite plus ferrite contents was determined by X-ray diffraction.

(4) Acid separated residues were examined by X-ray diffraction.

The following conclusions are drawn:

(1) The apparent increase in austenite in aging treatments at $1050{ }^{\circ} \mathrm{F}$ was a reversion of martensite, the A 2 tungsten type bodycentered cubic structure, to austenite, the A 1 copper type face-centered cubic structure.

(2) The hardening precipitate in the $17-7 \mathrm{PH}$ commercial alloy was the ordered $\alpha^{\prime}\left(\mathrm{B}_{2} \mathrm{CsCl}\right.$ type cubic structure) found by Underwood and associates [3] in a laboratory alloy and by Bradley $[4,5,6,7]$ in the $\mathrm{Fe}-\mathrm{Al}-\mathrm{Ni}$ system. The lattice constants for $\alpha \mathrm{Fe}$ and $\gamma$ phases were $2.8714 \mathrm{~A} \pm 0.00005$ and 2.909 $\mathrm{A} \pm 0.006$ respectively after $68 \mathrm{hr}$ aging treatment.

(3) The abrupt increase in strength and loss in ductility at aging temperatures from 850 to $1050{ }^{\circ} \mathrm{F}$ are caused by a precipitation of $\alpha^{\prime}$. The rapid recovery following initial loss in ductility and the slower loss in strength resulting from aging at $1050{ }^{\circ} \mathrm{F}$ are caused by a reversion of $\alpha \mathrm{Fe}$ to $\gamma \mathrm{Fe}$. The absence of recovery in ductility and the absence of a loss in strength at $970{ }^{\circ} \mathrm{F}$ and lower temperatures are caused by a lack of reversion of $\alpha \mathrm{Fe}$ to $\gamma \mathrm{Fe}$.

The authors acknowledge the cooperation of colleagues at the National Bureau of Standards who made significant contributions to this investigation, in particular P. D. Sarmiento, who prepared the extraction replicas for identifications of microconstituents by electron diffraction, and F. Brown who conducted the bulge tests.

\section{References}

[1] Adolph J. Lena, Precipitation reactions in iron-base alloys, Educational Lectures, 1957, Precipitation from Solid Solution, American Society for Metals, Cleveland, Ohio.

[2] D. C. Ludwigson and A. M. Hall, The physical metallurgy of precipitation-hardenable stainless steels, DMIC Report III, April 20, 1959; Battelle Mem. Inst., Columbus, Ohio.

[3] E. E. Underwood, A. E. Austin, R. E. Maringer, and G. K. Manning, The mechanism of hardening in 17-7 PH stainless steel, WADD Tech. Report 60-236, June 1960; Battelle Mem. Inst., Columbus, Ohio, Contract No. AF 33(616)-6521.

[4] A. J. Bradley and A. Taylor, An X-ray study of the FeNi-Al ternary equilibrium diagram, Proc. Roy. Soc. London 166, 353 (1938).

[5] A. J. Bradley, microscopical studies on the Fe- Ni-Al system, Pt. I, $\alpha+\beta$ alloys and isothermal sections of the phase equilibrium diagram, J. Iron and Steel Inst., London 163, 19 (1949). 
[6] A. J. Bradley, Microscopical studies on the Fe-Ni-Al system, Pt. II, The breakdown of the body-centered cubic lattice, J. Iron and Steel Inst., London 168, 233 (1951).

[7] A. J. Bradley, Microscopical studies on the Fe-Ni-Al system, Pt. III, Transformations of the $\beta$ and $\beta^{\prime}$ phases, J. Iron and Steel Inst., London 171, 41 (1952).

[8] G. Krauss, Jr., and B. L. Averbach, Retained austenite in precipitation hardening stainless steels, Trans. Am. Soc. Metals 52, 434 (1960).

[9] N. L. Carwile and S. J. Rosenberg, A study of 17-7 PH stainless steel, WADC Tech. Report 58-653 (June 1959); NBS, Washington, D.C. Contract No. AF 33 (616) $-57-7$.

[10] A. Taylor, X-ray metallography, pp. 499 and 513 (John Wiley and Sons, 1961).

[11] D. B. Ballard, Use of the bulge test for determining mechanical properties of stainless steel foil, Mat'ls. Research \& Stds. 1, 471 (June 1961).
[12] Precipitation processes in steels, Special Report No. 64 , Iron and Steel Institute, London, Papers 1, 2, and 3. (1958).

[13] Apparatus for Vacuum Evaporations, NBS Tech. News Bull., p. 30, (Feb. 1961)

[14] H. J. Goldschmidt, Interplanar spacings of carbides in steels, Metallurgia, 40, 103 (June 1949).

[15] Phase diagram in Metals Handbook, 1948 Edition, American Society for Metals, p. 1261.

[16] A. J. Cook and B. R. Brown, The constitution of ironnickel-chromium alloys at $550-800{ }^{\circ} \mathrm{C}$, J. Iron and Steel Institute, 171, 345 (1952).

[17] S. J. Rosenberg and D. R. Irish, Solubility of carbon in $18 \%$ chromium and $10 \% \mathrm{Ni}$ austenite, J. Research, NBS 48, 40 (Jan. 1952).

[18] F. C. Monkman, F. B. Cuff, and N. J. Grant, The effect of composition on the $\mathrm{M}_{\mathrm{s}}$ and decomposition temperatures in stainless steels, Metallurgy Reports, M.I.T. y, No. 2 (Feb. 1956).

(Paper 66C2-92) 